\title{
¿Es el esfuerzo una característica esencial de la voluntad? Una aproximación a William James desde la psicología de Tomás de Aquino
}

\author{
DAVID TÉLLEZ MAQUEO* \\ Universidad Panamericana (México) \\ detellez@up.edu.mx
}

\begin{abstract}
Resumen
William James hace del sentimiento de esfuerzo un elemento característico del querer; de modo que su presencia sería señal indiscutible de que se trata de un acto propiamente voluntario, y su ausencia una prueba de que la voluntad estaría faltando. Esta consideración aún vigente ha contribuido a la afirmación de que el poder de la voluntad depende del mayor o menor esfuerzo para ejecutar un acto: de donde, a mayor esfuerzo, mayor voluntad. El propósito de este artículo es mostrar que una consideración de la voluntad en estos términos está en desacuerdo con la perspectiva de Tomás de Aquino, el cual enseña la existencia de actos voluntarios que no cuestan trabajo. Como consecuencia de la postura aquiniana, la popular creencia de que los actos más valiosos son los más difíciles termina siendo cuestionable.
\end{abstract}

Palabras clave: Voluntad, esfuerzo, amor, atención, placer.

\section{Is the effort an essential feature of the will? An approach to William James from Thomas Aquinas's Psychology}

\begin{abstract}
William James puts forth the feeling of effort as an essential feature of the will in such a way that its presence would be an undeniable sign of a voluntary act, and its absence proves that the will is missing. This historically accepted consideration has contributed to the prevailing assumption that the power of will depends on the more or less effort to execute an act: the more effort one puts into operation, the more will one have. The purpose of this article is to show a consideration of the will according to these terms disagree with Thomas Aquinas's vision, who teaches that there are voluntary actions that don't take hard work. As a result of the aquinian stance, the common belief that the most valuable actions are the most difficult, ends up being disputable.
\end{abstract} Key words: Will, effort, love, attention, pleasure.

\footnotetext{
* Doctor en Filosofía por la Universidad de Navarra (España). Catedrático de Antropología Filosófica y Ética en el Departamento de Humanidades de la Universidad Panamericana. Miembro del Sistema Nacional de Investigadores del CONACYT. Autor de "Presentación, traducción y notas" de la obra de Tomás de Aquino: Cuestiones disputadas sobre el mal (2015); La importancia de los textos clásicos para una educación bumanista (2015); Gramática, lógica y retórica: un estudio histórico-filosófico del Trivium medieval (2014).
} 
La versatilidad del pensamiento de William James (1842-1910) como filósofo y psicólogo estadounidense, ha propiciado que su trabajo haya sido vinculado a diversas actitudes intelectuales contemporáneas. Desde aquella que lo ubica entre los estudiosos de la estética de la religión (Porterfield, 2014: 154-162) y la conciencia budista (Stanley, 2012: 201-211), pasando por los que ven en él un teórico del feminismo pacifista (Foust, 2014: 889-905), hasta los que se enfocan en facetas más conocidas de su obra, como las cuestiones propiamente psicológicas referentes al sentido común (Haddock Seigfried, 1983: 273-290) y al estudio científico de las emociones (Barbalet, 1999: 251-286). Uno de los nichos de su pensamiento menos explorados por parte de los filósofos radica en su psicología del acto volitivo, aspecto que como intentaré mostrar, guarda relación con la antropología de la voluntad en Tomás de Aquino, y más específicamente, con la ejecución como una de las etapas del acto voluntario según este último.

Independientemente de los elementos pragmatistas, funcionalistas o consecuencialistas que subyacen a su pensamiento, es de subrayar el interés que mantuvo por analizar los resortes del comportamiento humano a partir de las conclusiones de la ciencia experimental y el hecho de que mantuvo una perspectiva aristotélica de fondo como visión de la realidad basada en la experiencia sensible como fuente de conocimiento. Tampoco hay que olvidar que la metodología de la introspección basada en el conocimiento del propio sujeto, así como el análisis llevado a cabo por el Estagirita sobre nociones como la $\pi \rho 0 \alpha i ́ \rho \varepsilon \sigma \iota \varsigma$ o elección meditada (Aristóteles, 2000a: 163), no han podido ser completamente desconocidos para alguien como él, imbuido en las ciencias naturales y el progreso científico que marcó su época. Sin embargo, este análisis que aquí presento acerca de la voluntad y su relación con el esfuerzo también guarda puntos de contacto con relación a la visión que tiene Tomás, así como diferencias relevantes para una valoración sobre la postura de James a partir de la antropología tomasiana de la voluntad.

El tema de la voluntad y su relación con el esfuerzo sobre lo cual trata el presente trabajo suscita el interés personal por múltiples motivos, de los cuales destacan dos de ellos. El primero, es de tipo pedagógico. Cualquier proyecto de educación de corte humanista sigue descansando en la necesidad de educar la voluntad y de enseñar a la persona a elegir convenientemente, donde lo importante, como se sabe, no es sólo la capacidad de la voluntad de estar abierta a diversas opciones, sino que en dichas opciones los contenidos son valiosos en la medida en que llevan a la actualización 
del hombre según su naturaleza racional ${ }^{1}$. La cuestión entre esta educación y el tema del presente trabajo pasa por saber si una voluntad que elige lo que más trabajo involucra es necesariamente más valiosa para el sujeto en vías de educarse, que aquella otra que opta por lo que menos esfuerzo implica.

El segundo motivo de actualidad acerca del tema está vinculado a una impronta "neopelagiana" que alcanza a ciertos manuales de desarrollo humano. Aunque no hay duda del carácter formativo que encierra plantearse ideales difíciles de alcanzar para la mayoría, algo muy a tono con la magnanimidad como virtud aristotélica, también es un hecho que ser humilde resulta ser hoy "contracultural" en cuanto que ser humilde es contrario a una cultura que sobrestima el esfuerzo de cada uno por hacer las cosas por sí mismo. Esto que, repito, encierra frutos positivos, ha ocasionado por otra parte una sobrevaloración de lo que cuesta trabajo realizar. "Lo que no cuesta, no dura", "si las cosas que merecen la pena fueran fáciles entonces cualquiera las haría", se dice en sentido positivo para despertar los desafíos, pero también para justificar con ello que sólo las acciones arduas son dignas de ejecutarse, porque es en las acciones que implican esfuerzo donde, diría William James, radica el elemento esencial característico del querer.

El objetivo de este artículo es mostrar que una consideración de la voluntad en la que el sentimiento de esfuerzo y de tensión son el criterio para determinar cuándo estamos ante un acto propiamente voluntario, se enfrenta con ciertos desafíos desde la antropología de Tomás de Aquino, de cuya psicología se desprende que el esfuerzo llevado a cabo por el hombre para alcanzar un hábito es ciertamente un acto llevado a cabo por la voluntad, pero no es un ingrediente esencial del acto voluntario como señala James, lo cual se comprueba por la existencia de actos voluntarios que cuestan poco, o que no cuestan nada por encerrar un gran interés; actos cuya clase encuentran su fundamentación en algunas obras de Tomás de Aquino como las que aquí se presentan.

Para el desarrollo de su contenido, este artículo se divide en las siguientes partes: (1) una exposición de los puntos de contacto entre la psicología filosófica de Tomás de Aquino y William James; (2) una aproximación al esfuerzo como elemento esencial del la voluntad según James, seguida de (3) la correspondiente postura de Tomás de Aquino en torno a

1 Sobre el tema remitimos a Lobato (1994: 570), quien contrasta la visión tomasiana de la voluntad como tendencia del apetito volitivo a ser actualizado por un ser fuera de ella y cuyo movimiento va «de dentro afuera», con una visión moderna en la cual el movimiento de la voluntad va de «dentro hacia adentro», porque lo que mueve a la voluntad no es ya un ser extrínseco a ella (la realidad objetiva) sino el objeto de sus propios deseos, nada más contrario al amor, el cual supone un uso no dominativo de la voluntad, según afirma Alvira (1988: 48). 
la noción de esfuerzo de la voluntad; (4) un análisis de la relación entre esfuerzo y mérito en Tomás de Aquino; y (5) un comentario final a modo de conclusión.

1. Psicología tomasiana y jamesiana: AlgunOS puntos De CONТАСТО

Partiendo del habla cotidiana, es un hecho que existe una diferencia entre desear y querer. Aunque en el esquema tomasiano ambos constituyen actos tendenciales o apetitivos, el primero es fruto de un conocimiento sensitivo, mientras que el querer es un apetito procedente de un conocimiento intelectivo. Por su parte, en el esquema jamesiano, el deseo mantiene una diferencia con relación al querer consistente en el hecho de que el deseo acompaña al sentimiento de que no es posible alcanzar mi propósito. Pero cuando considero que el fin está en mi poder alcanzarlo, es porque quiero que el objeto deseable sea real. El querer es aquello por lo que lo deseable se vuelve real (James, 1947: 482). Con esto surge una primera idea que guarda relación con Tomás de Aquino. Aunque para éste el querer no se identifica con lo que está en mi poder alcanzar (pues incluso puedo querer lo imposible), es verdad que la deliberación como acto de la voluntad, opera "respecto de las cosas que están en nuestro poder" (Aquino, 1983: $134)^{2}$ de modo que si alguien deliberara sobre lo imposible parecerá que es un insensato, como sería, por ejemplo, querer ser inmortal en esta vida corruptible.

Una segunda constante que afecta por igual a las acciones voluntarias tanto en Tomás de Aquino (Aquino, 1989: 168-176) como en James (1947: 489) es el carácter imperativo de la voluntad, cuyas acciones vienen dadas en la forma de una orden o mandato, es decir, un elemento de asentimiento o resolución sobre lo que ha sido fruto de aquella deliberación previa acerca de lo que está en mi poder alcanzar, todo lo cual lleva implícito que ahí donde no existe tal mandato volitivo, se presentan movimientos inmediatos de nuestro cuerpo. No me refiero con ello a los llamados actus hominis en Tomás (v.g. circulación sanguínea, respiración, etcétera), o

2 "Los actos de la voluntad están totalmente en nuestra potestad, pues se dice que todos nuestros actos están en nuestra potestad en la medida en que son voluntarios" (Aquino, 1989: 172).

En el mismo tenor dice el Estagirita: "Deliberamos entonces sobre lo que está en nuestro poder y es realizable [...]. Y todos los hombres deliberan sobre lo que ellos mismos pueden hacer. Sobre los conocimientos exactos y suficientes no hay deliberación, por ejemplo, sobre las letras [...]; pero, en cambio, deliberamos sobre lo que se hace por nuestra intervención [...], por ejemplo, sobre las cuestiones médicas o de negocios" (Aristóteles, 2000a: 80). 
“ejecuciones primarias" como las denomina James (1947: 483), sino principalmente a esa clase de actos caracterizados por la ausencia de una orden expresa de la voluntad, como los llevados a cabo de manera espontánea. A esta clase de actos, a los que James denomina "acciones ideomotoras", pues son el resultado de un movimiento que surge directamente a partir de una sensación o idea sin mediar nada entre la concepción de un propósito y su ejecución, se refiere con los siguientes ejemplos:

Al hablar me doy cuenta de que hay un alfiler en el suelo o polvo en mi pantalón. Sin interrumpir la conversación, sacudo el polvo o recojo el alfiler. Para ello no he hecho resolución especial, ha bastado la mera percepción del objeto [...]. De igual modo me ocurre cuando, finalizado el almuerzo, me hallo comiendo nueces o uvas. La comida propiamente ya ha terminado; sin embargo, en el calor de la conversación no me doy cuenta de lo que hago; y la percepción de la fruta y la fugaz noción de que puedo comerla parece que me llevan fatalmente al acto ejecutado (James, 1947: 491).

Tomás de Aquino explica la existencia de esta clase de actos al hablar de la posibilidad de que haya actos moralmente indiferentes, en aquel lugar de su obra (Aquino, 2015: 105-106) donde señala que, junto a los actos buenos y malos intrínsecamente, existen otros actos que ni comportan algo conveniente a la razón ni algo que disiente de ella, sino que son moralmente indiferentes porque no proceden de una voluntad deliberada: como por ejemplo, levantar una estaca de la tierra (levare festucam de terra) o rascarse la barba (confricatio barbae) ${ }^{3}$.

Lugar aparte ocupan aquellos actos procedentes de una voluntad movida por un dinamismo como el del hábito, el cual, ni en Tomás de Aquino ni en James pueden considerarse como involuntarios ya que surgen de un mandato originario de la voluntad (imperium) en el principio de su ejecución y se ordenan a un fin específico, si bien es cierto que dicho mandato de la voluntad no debe reiterarse con cada uno de los actos continuos que acabarán por fijar el hábito, sino que dicho mandato se hace presente principalmente al comienzo de su formación. Esto explica por qué si ha sido necesaria la atención consciente y voluntaria en el surgimiento de los há-

\footnotetext{
3 Levantar una estaca de la tierra para hacer con ella una fogata y calentar los alimentos puede ser bueno, entre otras cosas, porque se ordena a un fin bueno. Y levantar esa misma estaca para golpear injustamente a otro puede ser malo. Pero el simple hecho de levantar una estaca de la tierra, tan pronto como la vemos tirada en el suelo, sin mediar ningún propósito para ello, es lo que correspondería a una acción moralmente irrelevante que no participa de bondad o maldad intrínseca. Esto es lo más cercano a una acción ideomotora en James, un movimiento en que tiene lugar una serie de procesos neuromusculares en los que la voluntad no concurre causalmente en lo más mínimo.
} 
bitos, una vez formados tienden a dispensar de ella, e incluso dicha atención se convierte en fuente de error. Pues al enfocarse en los elementos separados de un conjunto que funciona como un todo, la voluntad consciente corre el riesgo de aislarlos y desorganizar lo que se presenta como un sistema (v.g. si yo fuera consciente de cada una de las teclas del piano al momento de interpretar la partitura como un todo, acabaría por cometer errores en la ejecución de la pieza musical).

Esto que para Tomás de Aquino resultaba consistente con su doctrina sobre el origen de los hábitos (Aquino, 1989: 395-399) ${ }^{4}$, se relaciona con el siguiente ejemplo planteado por James:

Una persona se dice a sí misma "voy abajo", y antes de saberlo, ha echado a andar y ha abierto la puerta; todo ello merced a la idea de un fin acoplado a una serie de sensaciones directoras que sucesivamente se suscitan. Paece que nos habrán de faltar agudeza y certidumbre para lograr el fin cuando nos preocupamos del modo en que se sentirá el movimiento. Andamos mejor cuanto menos pensamos en la posición de nuestros pies [...]. Fíjese la mirada en el sitio deseado y la mano lo tocará; si se piensa en la mano, probablemente no se logrará el fin (1947: 489)

Existen otras semejanzas de menos relieve entre James y Tomás, como la existencia de distintas fases del voluntario ${ }^{5}$ : la concepción de la voluntad como facultad presente en cada una de dichas fases o la existencia de un surtido de ideas y experiencias ya existentes en la memoria como condición indispensable de cualquier movimiento voluntario. Pero la cuestión que genera mayor interés radica en sus diferencias, principalmente en la distinta consideración que sobre el acto voluntario mantienen entre sí ambos autores.

4 Según Tomás, el hábito es el resultado de una multiplicidad de actos que acaba por engendrar en las potencias apetitivas una determinada inclinación a ser movidas por la razón como principio activo. Lo importante es que es un proceso de fijación de conductas controladas por la voluntad: de un modo más firme al principio, pero menos consciente posteriormente a medida que la voluntad logra abatir poco a poco las tendencias descarriadas del irascible y concupiscible. Para ello, la voluntad se sirve de un acto de la razón por el que juzga que algo ha de ser apetecido conforme a determinados motivos y circunstancias.

5 Las doce fases mencionadas por Tomás (Aquino, 1989: 118-203), suelen ser reducidas por la manualística moderna a cuatro: fin, deliberación, decisión y ejecución. Sobre los inconvenientes de esta simplificación que ha hecho la psicología moderna caracterizada por una falta de matices y finura, pueden consultarse: Vernaux (1967: 155); Jolivet (1956: 479-481). 


\section{EL ESFUERZO COMO ACTO ESENCIAL DE LA VOLUNTAD SEGÚN JAMES}

Para explicar lo que caracteriza al acto voluntario, James parte del hecho empírico de que la mayoría de los actos de la vida cotidiana (andar, hablar, etc.) se producen sin necesidad de una deliberación para cada uno de tales actos particulares, y por ello mismo, sin necesidad de vencer ninguna resistencia: "todos los actos de nuestra vida diaria ocurren de este modo: [...] no exigen otro impulso que el aportado por el propio fluir del pensamiento" (James, 1947: 492). Y así, "la inmensa mayoría de las decisiones humanas son decisiones sin esfuerzo" (James, 1947: 502).

Pero esta ausencia de toda noción de conflicto en la mente como causa motora de la mayoría de las acciones puede llegar a verse interrumpida cuando eventualmente aparece en la mente alguna representación contraria a dicha inercia, que viene a "robarle" poder impulsivo. Según James, es en este momento en que la conciencia se hace presente en la forma de una orden o mandato que va en el sentido de la mayor resistencia cuando puede afirmarse que estamos ante un acto voluntario.

James resume toda la psicología de la volición con un ejemplo sencillo:

Sabemos lo que es levantarse de la cama una mañana fría en un cuarto sin calefacción [...]. No hay quien alguna vez, puesto en tal caso, no haya deliberado consigo mismo, a veces durante una hora, y aun así no haya llegado a resolverse. Pensamos que se va haciendo tarde, que los deberes cotidianos nos reclaman. Nos decimos: «tengo que levantarme, esto es vergonzoso», pero sigue pareciéndonos tan deliciosa la tibieza del lecho y tan cruel el frío de afuera, que la resolución va debilitándose y posponiéndose hasta que llega al borde de romper la resistencia y pasar al acto decisivo [...]. Se produce un lapso afortunado de conciencia: «basta, no debo seguir acostado». Consiguientemente, se producen enseguida efectos motores apropiados. Lo que paralizaba nuestra actividad y mantenía en estado de deseo y no de voluntad la idea de levantarnos era nuestra aguda conciencia del calor y frío en el periodo de lucha (1890: 524) ${ }^{6}$.

Para James, el acto voluntario es ciertamente un acto de decisión, pero también es una sensación porque al decidir sentimos que por nuestro acto voluntario inclinamos el fiel de la balanza en favor de las razones lógicas que por sí solas parecen impotentes para hacer descargar el acto. Pues a los motivos por los que se actúa, es necesario añadir la intensidad de una

\footnotetext{
6 Ordinariamente cito a James conforme a la edición castellana de su Compendio de Psicología (James, 1947). En algunas ocasiones, sin embargo, uso la edición inglesa de sus Principios de Psicología (James, 1890), en aquellos pasajes dudosos o más relevantes, en cuyo caso la versión final al castellano es obra propia.
} 
fuerza activa como la del esfuerzo para poder obrar eficazmente. Esto permite descartar la existencia de cualquier impronta de intelectualismo que pudiera existir en la psicología jamesiana ${ }^{7}$.

Aunque James reconoce las dificultades semánticas que entraña la palabra esfuerzoo (y más aún la noción de "cantidad de esfuerzo", tan problemática en psicología), ello no obsta para considerarlo base del acto voluntario. El esfuerzo que acompaña al querer y a la atención, más que identificarse con un asunto de tipo fisiológico o muscular, es un fenómeno mental que se produce cada vez que es evocado desde lo interno del hombre "un ideal que permite neutralizar las impresiones habituales e instintivas" (James, 1890: 548) ${ }^{8}$. Esforzarse implica afrontar mentalmente una idea como real. Por eso, "no son los afortunados a cuya cuna llevaron regalos sus hadas los que tienen problemas de voluntad, sino los héroes y los neuróticos" (1890: 548), que se mueven bajo grandes ideales y por un recto sentido del deber, los que suelen realizar actos de voluntad.

A diferencia del abúlico, en quien el ideal aparece como una voz lejana, como si sólo los motivos más bajos tuviesen eficacia impulsiva, en la esfera del esfuerzo, que es la esfera de la exigencia moral, el hombre siente el impulso activo que provocan los motivos superiores, es decir, los ideales, venciendo toda propensión o tentación?. ¿Qué es lo que ocurre cuando, por medio de la voluntad, el ideal se impone sobre una inclinación sensual grande? Aumenta la cantidad de esfuerzo. Si la propensión sensual es pequeña, igualmente pequeño será el esfuerzo. Pero ante la presencia de un gran antagonista que vencer, el esfuerzo acaba por agrandarse ${ }^{10}$.

\footnotetext{
Principalmente cuando admite que la voluntad puede desenvolverse al margen de motivos, como sucede con la creación estética (James, 1947: 501-502). Y es también en virtud de que no siempre se tienen motivos para actuar por lo que el acto voluntario se torna en algo que cuesta trabajo ejecutar. Pues en este caso "es la sombría resignación en aras del austero y pío deber, exento de todo premio mundano" (James, 1947: 502) aquello por lo que se procede a llevar a cabo la acción.

8 La prueba de que el esfuerzo volitivo y el esfuerzo muscular no se confunden es que existen casos en que se requiere de un gran esfuerzo de la voluntad, aunque la ejecución muscular sea insignificante, por ejemplo, levantarse de la cama y bañarse en una mañana fría.

9 La conclusión lógica es que el perezoso, el borracho, el cobarde, nunca hablan de su conducta en términos de conquistar y vencer sus impulsos ("he derrotado a mis fuerzas", "he vencido mi sobriedad", "he conquistado a la valentía"), sino que siempre usarán términos de inactividad ("olvidé mis ideales", "fui sordo al deber", etc.): "el sensualista nunca dirá que su conducta resulta de una victoria sobre los ideales; en cambio, el moralista hará ver que actúa venciendo sus propensiones" (James, 1890: 548).

10 En la Suma de Teología, 1-2, c55, a3, ad3, Tomás de Aquino afirma: "Tanto más perfecta se muestra la razón cuanto mejor puede vencer las debilidades del cuerpo y de las facultades inferiores. Por eso, la virtud humana, que se atribuye a la razón, se dice que se
} 
Y así, dado que James sitúa en este sentimiento de esfuerzo el estado psicológico de la voluntad, la acción de la voluntad termina sencillamente cuando el ideal logra reposada audiencia en la persona ("if they can once get a quiet hearing"), careciendo de importancia el que después se siga o no el acto: "la volición es un acto moral o psíquico puro y simple, hallándose absolutamente completo cuando se encuentra en él la idea estable. El despliegue de un movimiento es fenómeno supernumerario" (James, 1890: 560). La cuestión es, pues, determinar ¿cuándo el pensamiento de un acto dado llega a prevalecer en la mente de modo estable? Para James, la actuación esencial de la voluntad se produce en el momento en que el objeto difícil es seguido mentalmente con atención.

Dice James:

El esfuerzo de atención es, pues, el fenómeno esencial de la voluntad. Todo el mundo lo habrá podido experimentar en sí mismo, pues nadie habrá dejado de ser presa de alguna pasión intensa. ¿Qué es lo que constituye la dificultad para que un hombre subyugado por una pasión trivial obre como aconsejado por la más exquisita prudencia? No es ciertamente una dificultad física. Tan fácil es, físicamente [...] guardarse el dinero como malgastarlo; pasar de largo por la casa de una coqueta como dirigirse hacia ella: la dificultad es mental, y consiste en lograr que se destaque en la mente la idea de la acción prudente (1890: 562-563)

$\mathrm{El}$ acto fundamental de la voluntad se produce cuando a pesar de que otros excitantes puedan alzarse en la mente, gracias a un sostenido esfuerzo de atención, el objeto difícil de alcanzar termina por llenar todo el campo de la conciencia individual, hasta que al fin se sostiene por sí mismo en la mente con facilidad. De aquí que, para James, todo el drama de la voluntad sea un drama mental, pues su función es mantener fija la idea para evitar que oscile o se disipe, algo que sucedería naturalmente si no fuera porque la voluntad dispone de la capacidad de sostener una representación establemente ${ }^{11}$. Y aunque "tenemos ciertas ideas todo el tiempo [...] la única resistencia que cabe en lo posible a nuestra voluntad es la resistencia que tal idea ofrece a ser atendida" (James, 1890: 567).

perfecciona en la debilidad, no de la razón, ciertamente, sino en la debilidad del cuerpo y de las facultades inferiores".

11 "El punto de aplicación del esfuerzo de la voluntad yace siempre dentro del mundo interno, siendo una idea o una representación procedente de distintas clases de sensación. Por su naturaleza intrínseca o por la presencia de otras ideas, esta representación puede tender espontáneamente a apartarse de una conciencia vívida y estable. El esfuerzo mental puede ayudar a mantenerlo" (James, 1920: 218). 


\section{LA DIFICULTAD DE LA VOLUNTAD EN TOMÁS DE AQUINO}

Es sabido que, para Tomás de Aquino, la voluntad sólo se ejerce en función de un bien (Aquino, 1989: 118-131), que a su vez, es el objeto propio del amor (Aquino, 1989: 128). Por ello, todo el que ama quiere con su voluntad algún bien para su amado, ya se trate de Dios, del prójimo, de la propia alma o del propio cuerpo, que son las cuatro realidades que pueden tener como fin el amor (Aquino, 1933: 915). Si es verdad, como dice James, que el sentimiento de esfuerzo y de tensión es lo característico de la voluntad como facultad y del querer como acto de la voluntad, la dificultad formaría parte esencial del querer del amor. Todo parece indicar, sin embargo, que el parecer de Tomás de Aquino contrasta con tal apreciación, como se desprende del análisis de algunos textos a los que a continuación me referiré.

Un primer lugar relevante para el tratamiento del tema se encuentra en la Cuestión disputada sobre la caridad (Aquino, 1856: 583-586). A diferencia de James (1947: 521), quien distingue entre esfuerzo muscular y esfuerzo volitivo ya mencionados, Tomás distingue aquí dos clases de cosas difíciles de hacer: las que exigen ir en contra de algo (ex contrarietate) y las que tienen por objeto algo que nos desborda por tratarse de algo superior a nuestras fuerzas (ex excellentia obiecti) (Aquino, 1856: 585). A lo primero pertenecería la templanza, a lo segundo, lo que supera la comprensión intelectual o la capacidad física de una persona.

Posteriormente, partiendo de Aristóteles, Tomás comienza a plantearse el papel que desempeña el esfuerzo en su relación con el amor. El Estagirita ya había considerado que actos como irritarse, gastar dinero o dar dinero a otros están al alcance de cualquier persona, es decir, son fáciles de realizar (Aristóteles, 2000a: 69-70). Pero ejecutar esas mismas acciones, en el momento adecuado, por el motivo adecuado y de la manera adecuada, es algo difícil porque no todo el mundo puede hacerlo. Esto se refiere en general a todos los actos de la voluntad, pero también aplicaría al amor según Aristóteles. Pues para que éste fuera verdaderamente una virtud, sería necesario amar en el momento oportuno y por la razón y el modo debidos, si es verdad que el amor también debe estar sujeto a los principios del justo medio.

Por tanto, Tomás admite basado en Aristóteles que tanto los actos de la voluntad en general, así como los actos de la voluntad que ama, están sujetos a cierta tensión o dificultad en cuanto al hecho de que nadie nace siendo bueno, y a que todo hombre está llamado a hacerse bueno mediante el cultivo y práctica de la virtud ética. Todo esto está en sintonía con la necesidad jamesiana de "ponerle al corazón templada rienda" (James, 
1947: 529). La diferencia entre ambos autores parte de lo afirmado por Tomás en el siguiente lugar:

Puesto que la virtud se dirige hacia el bien, para que alguien adquiera cualquier virtud, debe estar dispuesto a ejecutar un bien de la manera conveniente, es decir, voluntariamente, fácilmente, placenteramente y establemente. Tales son las condiciones para poder hacer algo de una manera virtuosa. Y estas condiciones no están presentes en cualquier tipo de actos, sino que sólo pueden cubrirse cuando aquellos que realizan algo, aman el bien por el que lo realizan. Esto es así porque el amor es el principio de todos los afectos de la voluntad. Pues cuando amamos algo, mientras todavía no lo poseemos, lo deseamos. Y cuando ya lo poseemos, nos causa placer, así como tristeza todo aquello que se interpone para poseerlo. Además, aquello que se bace por amor se hace establemente, fácilmente y placenteramente. De esta manera, para hacer algo con virtud se require amar el bien al cual se ordena dicha virtud (Aquino, 1856: 584).

Es indudable que las cosas que la voluntad quiere pueden llegar a implicar un esfuerzo. Pero cuando lo que se quiere hacer forma parte de aquello que ya se ha hecho anteriormente en varias ocasiones, se genera en el individuo una disposición a hacer lo que originalmente ocasionaba un esfuerzo, cierto placer ${ }^{12}$. Esta disposición del alma a realizar algo bueno espontáneamente (prompte), establemente (firmiter) y placenteramente (delectabiliter) es a lo que Tomás denomina virtud. Pero como no todos los actos de la voluntad reúnen estas condiciones, la pregunta esencial que el Angélico se hace es: ¿cómo alcanzar la ejecución voluntaria de actos que reúnan estas tres condiciones? A ello va a responder: cuando aquellos que realizan algo, aman eso que realizan. Y por eso, para hacer algo con virtud, es necesario, previamente, amar el bien al cual se ordena mi acción ${ }^{13}$.

Para mostrar que el amor vuelve fácil lo difícil y áspero de la vida, Tomás (Aquino, 1856: 583) remite a un texto de Agustín de Hipona en el que éste describe la paradoja que encierra la cacería (venatio). En ella los

12 Aristóteles afirma: "los esfuerzos son molestos por cuanto son necesarios y forzosos, a no ser que sean habituales, porque en ese caso el hábito los convierte en placenteros" (2000b: 131).

13 ¿Y que es lo que hay que amar? Naturalmente, no lo que se hace (objeto), que podría tratarse de algo oneroso y difícil, sino principalmente aquello en vistas de lo cual se hace (fin), es decir, el bien por el que se realiza En todo esto podrá percibirse el influjo que sobre Tomás ejerció la doctrina aristotélica del bien arduo. Aunque ésta última se refiere a un apetito sensitivo e incluso animal, que nos impulsa a hacer algo que nos cuesta trabajo realizar, no por sí mismo (lo cual carecería de sentido) sino por el bien placentero que se seguirá posteriormente, también la voluntad puede llegar a querer algo que implica un esfuerzo, no por el esfuerzo mismo, sino por el bien que se desprende de mi acción: es lo que tiene lugar en aquel que ama lo que hace. 
cazadores tiene que afrontar serias dificultades de todo tipo para conseguir su objetivo: calores y fríos, fieras y peligros, ríos y precipicios, escasez de comida y bebida: "¿Cómo pueden soportar tener que beber y nutrirse de cosas viles, desagradables y en poca cantidad con tal de atrapar su presa? A veces, después de haber cazado el jabalí o el venado, el cazador siente más placer por haber atrapado su presa, que el placer de comerla una vez guisada" (Agustín, 1983: 300). ¿Cómo es ello posible? La respuesta sintética de Tomás y Agustín es ésta: lo que hace llevadera una actividad a los que la realizan a pesar de las dificultades que encierra, es el hecho de que verdaderamente quieren lo que hacen con todas las fuerzas de que es capaz su voluntad, pues "tener amor o afecto por algo es quererlo" (Aquino, 1856: 584).

Esto es lo más opuesto a lo que dice James sobre la voluntad. Tanto los que aman como los que no lo hacen tendrán que hacer cosas que exigen un esfuerzo. La diferencia está en que a los que aman les resultarán más ligeras, y a los que no aman, les resultarán pesadas: "porque todas las cosas feroces y atroces las hace fáciles y casi nulas el amor" (Agustín, 1983: $300)^{14}$. Es tradición acorde con esto que cuando a Tomás de Aquino le pregunta su hermana: ¿qué se requiere para llegar a ser santo?, el Angélico responde lacónica pero profundamente: "quererlo" (Mahan, 2008: 189).

De esto no se desprende que para Tomás no existan cosas difíciles por sí mismas para la voluntad ${ }^{15}$. Pero cuando se ha alcanzado la virtud para hacer algo, y principalmente cuando se ama el bien en función del cual se realiza, la acción que de suyo es difícil (lo que se demuestra por el hecho de que no cualquiera podría hacerla) se vuelve fácil o al menos se la tolera bien. Y cuando al paso del tiempo una actividad sigue siendo difícil por símisma, se vuelve fácil para la persona virtuos ${ }^{16}$ gracias al poder que tiene la virtud de modificar y robustecer la naturaleza del individuo.

14 La misma idea aparece en Tomás de Aquino (1861: 149): “omnia enim saeva et immania, prorsus facilia et prope nulla efficit amor".

15 En el plano laboral, se podría agregar una segunda advertencia: el que uno se apasione por aquello que realiza no significa que no vaya a equivocarse. Uno puede tener las mejores dotes naturales para ser un beisbolista, practicar el beisbol virtuosamente al punto de amarlo, y aun así, equivocarse. Pero esto no significa que uno tenga que optar por dedicarse a aquello que odia con tal de alcanzar la fortuna en los negocios. Por eso, ante la tesis de los que afirman que uno puede dedicarse válidamente a aquello que no le apasiona y aun así triunfar, desde la perspectiva de Tomás, es verdad que ello podría ocurrir, tan sólo objetaría una sola cosa: proceder así es proceder como el que no tiene la virtud, y por tanto, es un camino que puede recorrerse, pero será más largo, porque será menos confiable, estable y placentero.

16 "Manet enim, quantum in se est, difficile illud circa quod est virtus, adveniente virtute, sed quod facile fiat virtuoso, hoc est ex perfectione virtutis" (Aquino, 1856: 585). 


\section{EL ESFUERZO, ¿RAÍZ DE TODA ACCIÓN MERITORIA?}

En la Quaestio disputata de caritate (a8), Tomás de Aquino sale nuevamente al paso de otro argumento con el que algunos pretendían fundar una supuesta relación entre voluntad y esfuerzo. Explico el argumento partiendo de la distinción entre precepto y consejo.

Una antigua distinción existente entre diversos autores medievales, establece que según las obligaciones a las que uno atienda existen dos tipos de moral: de precepto y de consejo. En la primera se incluyen aquellas obligaciones a las que están llamados todos los hombres; en la segunda, por su parte, se incluyen aquellas obligaciones que deben abrazar sólo los individuos que aspiran a los más altos estándares de la perfección cristiana. A la luz de esta distinción, hay deberes más o menos claros de ubicar dentro de estas dos categorías de moral: así, por ejemplo, amar a nuestros padres se incluiría como parte de una moral de precepto, mientras que vivir la pobreza material formaría parte de una moral de consejo por tratarse de una obligación dirigida sólo a determinados individuos (como los miembros de órdenes religiosas).

Un asunto menos claro consistiría en determinar: ¿dónde se ubica el amor a los enemigos? ¿Se trata de un asunto de precepto o de consejo? Este es el contexto en que Tomás va a postular algunos elementos que sirven de pauta para responder al tema de la vinculación jamesiana entre la voluntad y el esfuerzo.

Para responder al problema, Tomás señala, por una parte, que amar a nuestros enemigos cae bajo (1) la necesidad de un precepto; y por otra, ello cae bajo (2) la plenitud del consejo. Explico brevemente la diferencia entre ambas categorías y el porqué de la doble respuesta.

(1) Estamos obligados en cuanto a sentimientos (affectu) y obras (effectu) se refiere a amar a todos nuestros prójimos y a rezar por todos ellos, sin excluir a los que no están vinculados con nosotros mediante algún lazo concreto, "como por ejemplo, a los que viven en India y Etiopía" (Aquino, 1856: 597). Pero no estamos obligados en cuanto a sentimientos y obras a ayudar en particular a todo aquel que no está vinculado con nosotros por algún otro lazo, con excepción de aquel que le ha tocado en suerte (pro sorte) estar en el mismo tiempo y espacio que nosotros: como por ejemplo, si viéramos a alguien en urgente necesidad, que sólo podría ser ayudado por nosotros (Aquino, 1856: 597).

Es decir, del hecho de que estemos obligados a amar a nuestros semejantes según el mandamiento del amor, no significa que debamos en acto, querer (affectu) o hacer el bien (effectu) a cada individuo en particular, sino a los que están más unidos a nosotros, como por ejemplo, por lazos de amistad o de familia. Pero no es de esta última clase de lazos la que nos une 
con los enemigos. Por tanto, como el único lazo que nos une con los enemigos es el amor, estamos obligados bajo la necesidad de un precepto, a amar con sentimientos y obras a los enemigos en general; y en particular cuando se encuentran en situación de urgente necesidad.

(2) Pero si existiera alguien que por causa de Dios manifestara hacia sus enemigos unos sentimientos y prácticas de amor semejantes a los que muestra con los que guardan lazos con él, ello pertenecería a la plenitud del amor, es decir, caería bajo lo que pertenece a un consejo, que no a un precepto (Aquino, 1856: 597). Por eso, amar a los enemigos no era considerado por Tomás de Aquino un precepto dirigido a todos los hombres, sino un consejo a los que aspiran alcanzar el más alto grado de la perfección moral, es decir, la plenitud en el amor. Amar a los enemigos era la culminación de un consejo (perfectio consilii).

Hasta aquí la respuesta dada por Tomás al problema de si el amor a los enemigos es un asunto de precepto o consejo. Ahora, la pregunta importante para nuestro tema relacionado con el valor latente de la dificultad o el esfuerzo para la virtud es la siguiente. ¿Qué es más meritorio: amar a los más cercanos a nosotros o a los enemigos? De acuerdo con la idea ampliamente reconocida actualmente, de que las cosas más difíciles son las más valiosas ("no pain, no gain", "no cross, no crown"), podría pensarse que para Tomás, amar a los enemigos sería más meritorio que amar a los hombres que guardan lazos con nosotros. Pero sorprendentemente el doctor de Aquino viene a indicar todo lo contrario, al decir que:

Hablando en sentido absoluto, si tenemos que considerar entre ambas acciones, es mejor amar a un amigo que a un enemigo; y mejor amar a Dios que a un amigo. Porque la dificultad de amar a un enemigo sólo se relaciona con la idea de mérito cuando mediante dicha acción se manifiesta la plenitud del amor, ante lo cual sucumbe toda dificultad. De esto se desprende que si el amor fuera tan completo que suprimiera toda dificultad, esa obra sería aún más meritoria (Aquino, 1856: 598).

De este modo, Tomás no hace ninguna concesión a la necesidad de aspirar a lo que nos cuesta mayor esfuerzo como si se tratara de lo más bueno, pues no es lo oneroso de una acción o trabajo lo que la vuelve meritoria, sino la mayor o menor perfección del amor con que se hace. Y como las cosas no son buenas por ser amadas sino amadas por ser buenas, mientras más buena sea una cosa, más mérito tiene amarla: "si es bueno amar algo bueno, es mejor y más meritorio amar lo que es más bueno" (Aquino, 1856: 598).

Por eso, si un trabajo lleva implícito en su ejecución poco esfuerzo o una gran carga de él, es un asunto menor para Tomás. Pues lo que lo hace valioso es el mucho o poco amor que mueve al acto. ¿Por qué amar a los 
amigos es más meritorio que amar a los enemigos, si amar a los enemigos es más difícil que amar a los amigos? Porque el amor a los amigos es más perfecto que el amor a los enemigos. Y sólo si se lograse amar a los enemigos con la misma perfección que a los amigos, es decir, mostrando sentimientos y obras semejantes a aquellos con los que amamos a nuestros seres queridos, el amor a los enemigos se volvería meritorio. Y así, las cosas difíciles sólo se vuelven meritorias cuando a través de ellas se revela un amor mayor. Tan grande, que lo que al principio es difícil, se vuelve cada vez más fácil o más llevadero.

Como es natural comprender, esta relación aquí planteada entre mérito y amor, también involucra a la voluntad, como lo demuestra el hecho de que Tomás (Aquino, 1989: 965), afirme que, el carácter meritorio del acto humano radica en que procede del libre albedrío, gracias al cual el hombre tiene la facultad de obrar por sí mismo actuando voluntariamente y no por causa de fuerzas externas al individuo. ¿Y cuáles son los actos más voluntarios de todos? Lo responde claramente Tomás: "los actos más voluntarios de todos son los que se hacen por amor. Y como una de las condiciones de cualquier acto meritorio es que proceda de un acto voluntario, el mérito debe atribuirse principalmente al amor" (Aquino, 1989: 966) Por tanto, si el amor es el acto más voluntario de todos, desde la perspectiva de Tomás el esfuerzo no puede ser el acto esencial de la voluntad.

¿Y no podría al menos ser verdad, como afirma James, que el fenómeno esencial de la voluntad fuera la capacidad de la mente de sostener de modo estable una representación en la conciencia, es decir, el esfuerzo de atención? El punto es que si efectivamente fuera así, ¿cómo se explicaría que hay actos de atención voluntaria que no exigen esfuerzo? En efecto, partiendo de los textos de Tomás de Aquino no parece encontrarse justificación para afirmar que la voluntad está determinada por el esfuerzo de atención. Para él, es un hecho que hay actos de atención voluntaria que cuestan poco. Incluso, hay algunos que más bien causan placer cuando encierran un interés. Y esto es resultado de la existencia de una materia cognoscible apta para el que la conoce, y de un sujeto con la disposición adecuada para conocerla ${ }^{17}$.

Hablando principalmente del sujeto que conoce, aprender es placentero porque descansa en un deseo de saber y aprender. $Y$ ninguno de estos deseos es forzado, sino más bien, conforme con el sentido de la propia naturaleza humana (Aristóteles, 2000c: 57). Por eso, cuando Aristóteles

\footnotetext{
17 "Habrá placer en la operación cuando sean como deben tanto el objeto por conocer, que puede ser lo sensible o inteligible, así como el sujeto mismo, que es el que discierne mediante el sentido o el que conoce mediante el intelecto. Esto sucede porque cuando en la parte activa y en la parte pasiva permanece una relación recíproca por la cual están referidos uno al otro, permanecerá el placer como efecto" (Aquino, 1983: 554-555).
} 
plantea que "toda acción forzada es dolorosa" (2000b: 131), lo que implícitamente afirma es que las acciones voluntarias son placenteras, o al menos algunas de ellas (siempre y cuando no quiera voluntariamente lo que me cuesta trabajo o me desagrada). Esta existencia de acciones voluntarias que por sí mismas pueden ser placenteras según Tomás de Aquino, es ya un rasgo importante para ilustrar su distinta visión que tiene de la voluntad con relación a la de James, que hace del esfuerzo lo característico de la voluntad.

Un último punto con relación al esfuerzo de la atención que cabría señalar se relaciona con algunas claves que aporta el Angélico al hablar de la oración en su Comentario a las Sentencias de Pedro Lombardo. Así, contra los que pensaban que no era lícito pedir algo en la oración, Tomás no sólo acepta que es lícito al que ora pedir ciertas cosas; más aún, reconoce basándose en Aristóteles (2000a: 100) que "mientras más concretas sean las cosas que debe uno pedir en la oración, mayor será el fervor con que se les deseará" (Aquino, 1947: 748). Lo que esto quiere decir para el fraile dominico (dejando éste a salvo que la oración es un acto de la facultad apetitiva antes que un acto de la razón práctica) es que en la medida en que la mente atiende en la oración a la cosa concreta, aumenta el afecto con que se espera recibir aquello que se pide. Por eso, para el Angélico, la atención voluntaria en la oración es plenamente compatible con el afecto que provoca la actividad de orar, algo que no podría suscribir James según el cual el ingrediente esencial de la atención es nuevamente el esfuerzo, el cual se produce cuando el pensamiento de un acto dado llega a prevalecer en la mente de un modo estable ${ }^{18}$.

No es que Tomás reste importancia a dicha estabilidad en la atención, como lo demuestra el hecho de estar consciente de la necesidad de evitar las distracción (evagatio) que suele presentarse ante aquel que eleva su alma hacia Dios ("Dios no escucha la atención que se hace sin intención", "cuando oréis a Dios...meditad en vuestro corazón lo que pronunciáis con la boca”: Aquino, 1994: 52). Pero también está consciente de que por su natural flaqueza, el espíritu humano no puede permanecer largo tiempo en las alturas. De aquí que la distracción del espíritu, cuando uno no se distrae a propósito, no suprime el fruto de la oración. Por eso, ésta puede verse interrumpida válidamente sin que carezca de mérito ${ }^{19}$. Sobre esta licitud de

18 "Tenemos ya las cosas en tal punto que vemos que todo lo implicado en cualquier clase de volición es la atención con esfuerzo. En suma, la actuación esencial de la voluntad, cuando es más voluntaria, se halla al atender un objeto difícil y mantenerlo firme en la mente" (James, 1947: 520-521).

19 "Para este efecto (mérito) no se requiere que la atención se mantenga de principio a fin, sino que la virtualidad de la intención inicial con que alguien se acerca a orar hace 
las interrupciones no intencionales, no figura nada semejante en el lugar donde James se refiere al esfuerzo de la atención.

De todo esto, no significa que la atención en Tomás no demande esfuerzo como para James. Pero ciertamente implica algo con lo cual se desmarca de la postura del psicólogo americano: que puede haber actos de voluntad sin que vayan acompañados de un esfuerzo de la atención. La razón última de ello, como ya hemos dicho, es que los actos más voluntarios de todos son los que se hacen por amor, lo cual confirmaría el hecho de que la oración es de los actos más voluntarios que existen, teniendo precisamente al amor a Dios como uno de sus fines esenciales.

\section{COMENTARIO FINAL}

Dada la importancia que ejerce el concepto de esfuerzo en la psicología de William James como "una de esas ideas universales que pertenece con necesidad al mobiliario intelectual de toda mente" (Jammer, 1967: 689), no es de extrañar que la considere el único sentido que nos pone en estrecho contacto con la realidad, toda vez que "la realidad se revela a sí misma en la forma de una fuerza" (James, 1920: 213). Esta valoración antropológica tan elevada del esfuerzo explica su estrecha relación con el querer y la atención, siempre presente en éstos últimos.

A pesar de los puntos de contacto que mantiene su psicología con la de Tomás de Aquino, he querido mostrar que la relación entre voluntadesfuerzo-mérito presente en James, viene a estar sustituida en Tomás por la relación entre voluntad-amor-mérito, de modo que:

a) Para el primero, la voluntad se mide por la mayor o menor cantidad de esfuerzo invertida en cada acto. Para el segundo, en cambio, la voluntad se mide por la mayor o menor perfección del amor con que se hace algo.

b) Para el primero, el esfuerzo es directamente proporcional al poder del querer: a más esfuerzo, más voluntad; y a menos esfuerzo, menos voluntad. Para el segundo, el esfuerzo sería inversamente proporcional al poder del querer. La razón de ello es que mientras más ama algo la voluntad (o porque el objeto amado es de suyo muy bueno o porque además se le ama con gran intensidad), menor es el esfuerzo que hay que desplegar para alcanzarlo. Y viceversa, cuando la voluntad ama poco, mayor es el esfuerzo que nos cuesta para adquirirlo.

A esto último se refería Carlos Llano (1997: 170) cuando basándose en Tomás, planteaba una peculiar dialéctica entre la meta magnánima de la voluntad y el esfuerzo para adquirirla, la cual se resume en lo siguiente:

meritoria la oración entera, tal como sucede en los demás actos meritorios” (Aquino, 1994: 52). 
cuando las metas son altas, las dificultades se hacen pequeñas. Porque con tal de alcanzar fines tan amables o amados, la voluntad es capaz de desplegar fuerzas insospechadas, las cuales terminan por abatir o ver reducidos al mínimo los obstáculos que van surgiendo, por muy grandes que sean las dificultades. Por el contrario, cuando las metas son pequeñas, las dificultades se hacen grandes. Porque de una mediocridad pequeña no pueden brotar las fuerzas suficientes para afrontar ni siquiera las menores dificultades. Quizás aquí radique la explicación psicológica de por qué cuando los equipos de fútbol juegan con rivales grandes, los equipos juegan bien. Y por el contrario, cuando los equipos de fútbol juegan con rivales pequeños, los equipos juegan mal. Porque la disposición de la voluntad ante una meta alta, se ensancha con la meta misma, o se empequeñece ante lo pequeño de la meta por adquirir.

En lo planteado aquí por Tomás radicaría la fundamentación última de un hecho de la vida cotidiana: "the more we love it, the more we endure it". Las personas que más nos cansan, no son las más antipáticas, sino las que no amamos. Se sufre al prójimo según se le ama. Lo cual, llevado al terreno de la vida que se asoma cada mañana como algo insuperable, significa que lo que cansa y lo que cuesta no es la vida difícil, sino el peso de llevarla sin alegría.

\section{REFERENCIAS}

-Agustín de Hipona (1983). Obras. Vol. 10: Sermones (51-116). (L. Ciruello, M. Ma Campelo, C. Morán y P. de Luis, Trads.). Madrid: B.A.C.

-Alvira, R. (1988). Reivindicación de la voluntad. Pamplona: EUNSA.

-Aquino, T. de. (1856) Quaestiones disputatae cum quolibetis. Vol. 8/1: Quaestio disputata de caritate. Parma: Fiaccadori.

-Aquino, T. de (1861). Catena aurea in quatuor evangelia. Vol. 11/1: Catena aurea in Matthaeum. Vol. 11. Parma: Fiaccadori.

-Aquino, T. de (1933). Scriptum super Sententiis Magistri Petri Lombardi. Vol. 3. Paris: Lethielleux.

-Aquino, T. de (1947). Scriptum super Sententiis Magistri Petri Lombardi. Vol. 4. Paris: Lethielleux.

-Aquino, T. de (1983). Comentario de la Ética a Nicómaco de Aristóteles. (Ana María Mallea, Trad.). Buenos Aires: CIAFIC ediciones.

-Aquino, T. de (1989). Suma de Teología. Vol. II. Parte I-II. Madrid: Biblioteca de Autores Cristianos.

-Aquino, T. de (1994). Suma de Teología. Vol. IV. Parte II-IIb. Madrid: Biblioteca de Autores Cristianos.

-Aquino, T. de (2015). Cuestiones disputadas sobre el mal. (Segunda edición). (Ezequiel Téllez, Trad.). Pamplona: EUNSA.

-Aristóteles (2000a). Ética Nicomáquea. (J. Pallí Bonet, Trad.). Madrid: Gredos. 
-Aristóteles (2000b). Retórica. (Q. Racionero, Trad.). Madrid: Gredos. -Aristóteles (2000c). Metafísica. (Tomás Calvo, Trad.). Madrid: Gredos.

-Barbalet, J. M. (1999). William James'Theory of Emotions: Filling in the Picture. Journal for the Theory of Social Behavior, 29(3), 251-286.

-Foust, M. (2014). The Feminism Pacifist of William James and Mary Whiton Calkins. Hypatia, 29(4), 889-905.

-Haddock Seigfried, Ch. (1983). The Philosopher's Licence: William James and Common Sense. Transactions of the Charles S. Pierce Society, 19(3): 273-290.

-Jammer, M. (1967). Psychological Origins of the Concept of Force. In D. Borchert (Ed.). Encyclopedia of Philosophy. Farmington Mills, MI: Thomson-Gale.

-James, W. (1890). The Principles of Psychology (Vol. II). New York: Henry Holt.

-James, W. (1920). The Feeling of Effort. Collected Essays and Reviews. New York: Longmans.

-James, W. (1947). Compendio de Psicología. (A. Salcedo, Trad.). Buenos Aires: EMECÉ.

-Jolivet, R. (1956). Tratado de filosofía. (Vol. 2: Psicología). (L. de Sesma, Trad.). Buenos Aires: Carlos Lohlé.

-Llano, C. (1997). Dilemas éticos de la empresa contemporánea. México: Fondo de Cultura Económica.

-Lobato, A. (1994). El pensamiento de santo Tomás de Aquino para el hombre de hoy (Vol. I: El hombre en cuerpo y alma). Valencia: EDICEP.

-Mahan, F. (2008). God alone is the truth and the way. How to survive the decline of America. Bloomington, IN: iUniverse.

-Porterfield, A. (2014). William James and the Modernist Esthetics of Religion. Church History, 83(1), 154-162.

-Stanley, S. (2012). Intimate distances: William James' introspection, Buddhist mindfulness, and experiential inquiry. New Ideas in Psychology, 30(2), 201-211.

-Vernaux, R. (1967). Filosofía del hombre. (L. Medrano, Trad.). Barcelona: Herder.

Sumario: Introducción; 1. Psicología tomasiana y jamesiana: algunos puntos de contacto; 2. El esfuerzo como acto esencial de la voluntad según James; 3. La dificultad de la voluntad en Tomás de Aquino; 4. El esfuerzo ¿raíz de toda acción meritoria?; Comentario final; Referencias. 